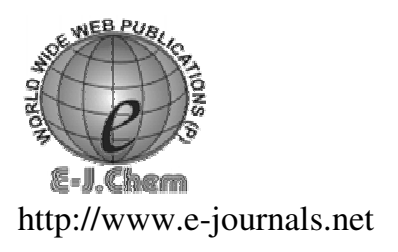

ISSN: 0973-4945; CODEN ECJHAO

E-Journal of Chemistry

Vol. 5, No. 2, pp.233-242, April 2008

\title{
Utilization of Sago Waste as an Adsorbent for the Removal of Cu(II) Ion from Aqueous Solution
}

\author{
P.MAHESWARI ${ }^{\#}$, N.VENILAMANI ${ }^{\#}$, S.MADHAVAKRISHNAN $\$$, \\ P.S.SYED SHABUDEEN, R.VENCKATESH ${ }^{*}$ and S.PATTABHI ${ }^{\$}$
}

\#Department of Chemistry, PSGR Krishnammal College for Women, Coimbatore ${ }^{\$}$ Department of Environmental Sciences, PSG College of Arts and Science, Coimbatore Department of Chemistry, Kumaraguru College of Technology, Coimbatore, Tamil Nadu

rvenckat@gmail.com

Received 20 March 2007; Accepted 1 May 2007

\begin{abstract}
The preparation of activated carbon (AC) from sago industry waste is a promising way to produce a useful adsorbent for $\mathrm{Cu}(\mathrm{II})$ removal, as well as dispose of sago industry waste. The AC was prepared using sago industry waste with $\mathrm{H}_{2} \mathrm{SO}_{4}$ and $\left(\mathrm{NH}_{4}\right)_{2} \mathrm{~S}_{2} \mathrm{O}_{8}$ and physico-chemical properties of $\mathrm{AC}$ were investigated. The specific surface area of the activated carbon was determined and its properties studied by scanning electron microscopy (SEM). Adsorptive removal of $\mathrm{Cu}$ (II) from aqueous solution onto AC prepared from sago industry waste has been studied under varying conditions of agitation time, metal ion concentration, adsorbent dose and $\mathrm{pH}$ to assess the kinetic and equilibrium parameters. Adsorption equilibrium was obtained in $60 \mathrm{~min}$ for 20 to $50 \mathrm{mg} / \mathrm{L}$ of $\mathrm{Cu}$ (II) concentrations. The Langmuir and Freundlich equilibrium isotherm models were found to provide an excellent fitting of the adsorption data. In Freundlich equilibrium isotherm, the $\mathrm{R}_{\mathrm{L}}$ values obtained were in the range of 0 to 1 (0.043 to 0.31 ) for $\mathrm{Cu}(\mathrm{II})$ concentration of 10 to $100 \mathrm{mg} / \mathrm{L}$, which indicates favorable adsorption of $\mathrm{Cu}(\mathrm{II})$ onto Sago waste carbon. The adsorption capacity of $\mathrm{Cu}(\mathrm{II})$ (Qo) obtained from the Langmuir equilibrium isotherm model was found to be $32.467 \mathrm{mg} / \mathrm{g}$ at $\mathrm{pH} 4 \pm 0.2$ for the particle size range of $125-250 \mu$. The percent removal increased with an increase in $\mathrm{pH}$ from 2 to 4 . This adsorbent was found to be effective and economically attractive.
\end{abstract}

Keywords: Activated carbon, Sago carbon, Adsorption, Copper removal

\section{Introduction}

Water is essential for survival. But today about 200 million people in India do not have access to safe drinking water due to water pollution ${ }^{1}$. Any change in physical, chemical or biological properties of water is known as water pollution. Heavy metal is important role of water pollution. 
The heavy metals are continuously released into the aquatic eco system from natural process such as volcanic activity and weathering of rocks. The effluents from mining, ore processing, metal processing, metal polishing, cleaning, paint manufacturing and battery manufacturing industries and acid rain contribute for the increasing metal loads in the water bodies ${ }^{2}$. The heavy metal contamination of the water system is responsible for serious diseases and death. Copper is one of the few metallic elements found in the earth's crust. It constitutes $70 \mathrm{mg} / \mathrm{kg}$ of the earth's crust, occurring as a constituent of several ores like, chalcopyrite $\left(\mathrm{CuFeS}_{2}\right)$, which is about $50 \%$ of total world copper deposits. Copper was the first metal used for men for utility purpose. Large number of important alloys contains copper as the principle element ${ }^{3}$. Environmental pollution due to copper arises from industrial and agricultural operations. Copper has broad industrial applications, such as alloy industries, paper and pulp; basic steel works foundries and petroleum refining industries ${ }^{4}$. Copper finds its way to water bodies through wastewater from copper wire mills, coal burning industries, tanning, insecticides and fungicides producing industries ${ }^{5}$. Copper is a trace element that is drinking water essential for most animals, including humans of that iron metabolism and maintenance of blood vessels. In India acceptable limits of $\mathrm{Cu}$ is $3 \mathrm{mg} / \mathrm{L}$. Higher concentration of copper is cause neuro toxicity commonly known as "Wilson's disease" due to the deposition of copper in the lenticular nucleus of the brain and liver. The other effect of copper to human includes congestion of nasal mucous membranes and pharynx, ulceration of nasal septum and metal fume fever. Eye irritation has been reported by factory workers exposed to copper dust. In some individuals, exposure to copper metal produces dermatitis ${ }^{6}$. Acute poisoning due to excessive amounts of copper salts may produce hematemesis, melena, coma and jaundice. Copper bound to albumin is considered to be the transport form of $\mathrm{Cu}$ (II) in blood. Copper deficiency causes Menke's disease ${ }^{7}$. Hence it is essential to remove $\mathrm{Cu}$ from industrial wastewater before discharging in to natural water sources to meet National Regulatory Standards as well as to protect public health. Conventional treatment methods for heavy metals containing waste water, chemical precipitation, Ferrite treatment system, sulphate precipitation, solvent extraction, evaporation, xanthate process etc., but due to operational demerits and the treatment cost is high .The need for cost effective and economic removal of toxic heavy metals from waste water resulted in a research for non-conventional materials and methods. Several low cost adsorbents include sawdust, orange peel, almond husk, parthenium etc.

The objective of the present study is to be prepare and characterize quality evaluate the efficiency of using sago waste carbon as an adsorbent for the removal of $\mathrm{Cu}$. The adsorption study was carried out systematically involving various parameters such as $\mathrm{pH}$, agitation time and adsorption dose.

\section{Experimental}

\section{Adsorbent}

Sago waste was collected from the sago industry in Salem district, Tamilnadu state; India, and was used as the source of activated carbon. Sago industry waste was subjected to chemical activation by the addition of $50 \% \mathrm{H}_{2} \mathrm{SO}_{4}$ and $\left(\mathrm{NH}_{4}\right)_{2} \mathrm{~S}_{2} \mathrm{O}_{8}(0.5 \%$ w/w with constant stirring at room temperature for 0.5 hour. The charred material was kept in hot air oven at $105 \pm 5{ }^{\circ} \mathrm{C}$ for 12 hour and was washed with distilled water ( 5 times). This material was soaked in $5 \% \mathrm{NaHCO}_{3}$ solution and allowed to stand overnight to eliminate the residual acid from the pores of the carbon. The material was washed with distilled water until the $\mathrm{pH}$ of the slurry reached $6 \pm 0.5$. Then it was dried in a hot air oven at $105 \pm 5{ }^{\circ} \mathrm{C}$ for 3 hour. The dried material was ground and sieved to get a product with a particle size range of $125-250 \mu$, which was used for this study. 


\section{Adsorbent characterization}

The physico-chemical properties of the carbon were presented in Table 1. The BrunauerEmmett-Teller (BET) surface area was determined using computer controlled nitrogen gas adsorption analyzer at $-196{ }^{\circ} \mathrm{C}$. Surface functional groups on the carbon were evaluated by adsorption experiments know as the Boehm technique ${ }^{12}$, based on the selective neutralization of surface acid groups by varying strengths of bases and basic groups by a strong acid. The $\mathrm{pH}_{\mathrm{ZPC}}$ for the sorbent was determined using the $\mathrm{pH}$ equilibrium method described by Kadirvelu et $a l^{11}$ and Xiaoge et $\mathrm{al}^{13}$. Elemental analysis of $\mathrm{C}, \mathrm{H}, \mathrm{N}$, and $\mathrm{O}$ (by difference) in the activated carbon was carried out on a Perkin Elmer elemental analyzer. Other parameters were analyzed using standard methods ${ }^{11}$.

Table 1. Properties of the activated carbon used for this study

\begin{tabular}{lc}
\hline Parameter & Value \\
\hline pH of 1\% solution & 7.1 \\
pH ZPC & 5.7 \\
Moisture, \% & 4.33 \\
Cation exchange capacity, meq/g & 0.75 \\
Carbon, \% & 65.0 \\
Hydrogen, \% & 2.0 \\
Nitrogen, \% & 3.0 \\
Oxygen, \% (by difference) & 30.0 \\
Yield, \% & 78.0 \\
Ash, \% & 12.0 \\
Apparent density, g/mL & 0.75 \\
Decolorizing power, mg/g & 55.5 \\
Matter soluble in $\mathrm{H}_{2} \mathrm{O}, \%$ & 5.5 \\
Matter soluble in $1 \mathrm{M} \mathrm{HCl,} \mathrm{\%}$ & 8.0 \\
Porosity, \% & 80.0 \\
*BET Surface area, ${ }^{2} / \mathrm{g}$ & 625.0 \\
Surface acid groups, meq/g & \\
I Carboxyl $\quad$ Lactonic & 1.20 \\
II $\quad$ Parbonyl & 1.80 \\
III $\quad 0.90$ \\
IV Total basic groups, meq/g & 1.60 \\
Pore volume, mL/g & 1.10 \\
* BET surface area corresponds to the particle size $125-250 \mu \mathrm{m}$.
\end{tabular}

\section{Batch adsorption studies}

A stock solution of $1000 \mathrm{mg} / \mathrm{L}$ of $\mathrm{Cu}$ (II) was prepared by dissolving $3.929 \mathrm{~g}$ of $\mathrm{CuSO}_{4}$ in doubly distilled water acidified with $5 \mathrm{~mL}$ of conc. $\mathrm{H}_{2} \mathrm{SO}_{4}$ to prevent hydrolysis and diluting to $1000 \mathrm{~mL}$. Batch adsorption test consisted of by mixing $50 \mathrm{mg}$ of adsorbent and $50 \mathrm{~mL}$ of $\mathrm{Cu}$ (II) solution of a desired concentration at an initial $\mathrm{pH} 4.0 \pm 0.2$ in $100 \mathrm{~mL}$ conical flasks and agitating the flasks in a mechanical shaker at $170 \mathrm{rpm}$ for predetermined time intervals at room temperature $\left(30 \pm 2{ }^{\circ} \mathrm{C}\right)$. After the agitation the adsorbate and adsorbent were separated by centrifugation at $3000 \mathrm{rpm}$ for minutes and the $\mathrm{Cu}$ (II) content in the solution was estimated spectrophotometrically at $445 \mathrm{~nm}$. The effect of agitation time on percent removal was studied using $\mathrm{Cu}$ (II) concentrations of 20 $50 \mathrm{mg} / \mathrm{L}$. The effect of carbon dose was tested using $\mathrm{Cu}(\mathrm{II})$ concentrations of 25 and $50 \mathrm{mg} / \mathrm{L}$ by varying the carbon dose between 25 and $250 \mathrm{mg}$ per $50 \mathrm{~mL}$ of solution. 
Freundlich adsorption isotherm data was obtained from the studies on the effect of carbon dose on the $\mathrm{Cu}(\mathrm{II})$ removal. Initial adsorption coefficients and Lagergren adsorption rate constants were obtained from the effect of agitation time on $\mathrm{Cu}$ (II) removal. Different ranges of particle sizes of the adsorbent were used to obtain the percent removal in $\mathrm{Cu}$ (II) concentration of $20 \mathrm{mg} / \mathrm{L}$. The effect of $\mathrm{pH}$ on $\mathrm{Cu}$ (II) removal was studied using $\mathrm{Cu}$ (II) concentrations of $20 \mathrm{mg} / \mathrm{L}$, by varying the initial $\mathrm{pH}$ of the solutions between 2 and 9 using $\mathrm{HCl}$ and $\mathrm{NaOH}$ for $\mathrm{pH}$ adjustment.

\section{Results and Discussion}

\section{Adsorbent characterization}

The results of sorbent characterization experiments are summarized in Table 1 . The surface morphology of the activated carbon was examined using scanning electron microscopy (SEM), the corresponding SEM micrographs being obtained using a JSM-840 microscope (JEOL Techniques Ltd., Japan) at 2500× magnification (Figure 1). At such magnification, the activated carbon particles showed rough areas of surface within which micropores were clearly identifiable. The BET surface area was higher $\left(625 \mathrm{~m}^{2} / \mathrm{g}\right)$ than those of some other carbons prepared from agricultural wastes such as peanut hull $\left(208 \mathrm{~m}^{2} / \mathrm{g}\right)$, coir pith $\left(595 \mathrm{~m}^{2} / \mathrm{g}\right)$, eichhornia $\left(266 \mathrm{~m}^{2} / \mathrm{g}\right)$ cassava peel $\left(200 \mathrm{~m}^{2} / \mathrm{g}\right)$ and coconut tree saw dust carbon $\left(325 \mathrm{~m}^{2} / \mathrm{g}\right)$ which is more important for adsorption processes ${ }^{8,10,11}$. Specific acidic groups were also measured using Boehm's method and the results were comparable with those of activated carbons prepared from other agricultural wastes ${ }^{8,11}$. It is very important to know the distribution and concentration of functional groups present on the carbon surface in order to better understand the adsorption process mechanism. Lactonic groups are present in high concentration in activated carbon, followed by carbonyl, carboxyl basic and phenolic groups. It has been reported that carboxyl groups dissociate in the $\mathrm{pH}$ range 3-7. In fact, it is noted that a considerable increase in $\mathrm{Cu}$ (II) sorption capacity occurs at or near this $\mathrm{pH}$ range. This makes the present activated carbon an excellent adsorbent for treatment of $\mathrm{Cu}(\mathrm{II})$-containing water.

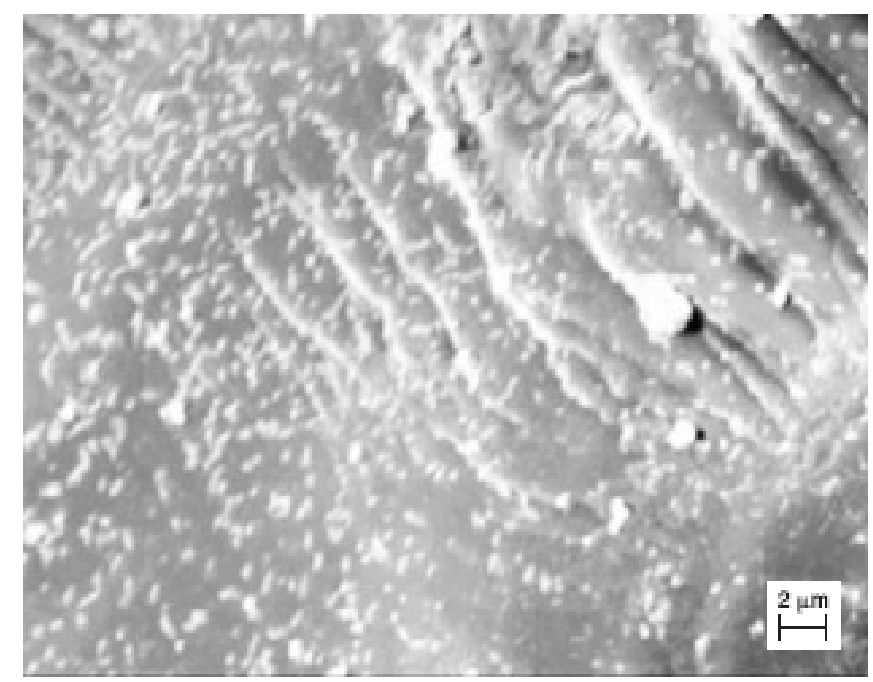

Figure 1. SEM micrograph of the surface of sago waste carbon, Magnification- 2500x 


\section{Effect of agitation time and initial $\mathrm{Cu}(\mathrm{II})$ ion concentration on $\mathrm{Cu}(\mathrm{II})$ adsorption}

The optimum equilibrium time was found out by using different concentrations of metal ion solution at $\mathrm{pH} 4 \pm 0.5$ (Figure 2). The effect of agitation time and initial metal ion concentration on adsorption of $\mathrm{Cu}$ (II) by sago waste carbon. The removal rate was rapid initially and then gradually diminished to attain an equilibrium time beyond which there was no significant increase in the rate of removal. The equilibrium was attained for 60 minutes for all the concentration studies. It should be noted that the contact time required for all metal ion concentrations was very short for the removal of $\mathrm{Cu}(\mathrm{II})$ which is an important parameter for economic wastewater application. At equilibrium time the amount adsorbed was 15.3, 20.08, 25.78 and $30.79 \mathrm{mg} / \mathrm{g}$ for the concentrations $20,30,40$ and $50 \mathrm{mg} / \mathrm{L}$ respectively. Similar results have been reported for $\mathrm{Cu}(\mathrm{II})$ adsorption ${ }^{14-16}$. It is very clear from the results that the agitation time required for maximum uptake of metal ion by using sago carbon is less when compared to other adsorbents. The metal ion adsorption $v s$ time curves were single, smooth and continuous leading to equilibrium suggesting the possibility of the formation of monolayer coverage of metal ions on carbon surface ${ }^{17}$.

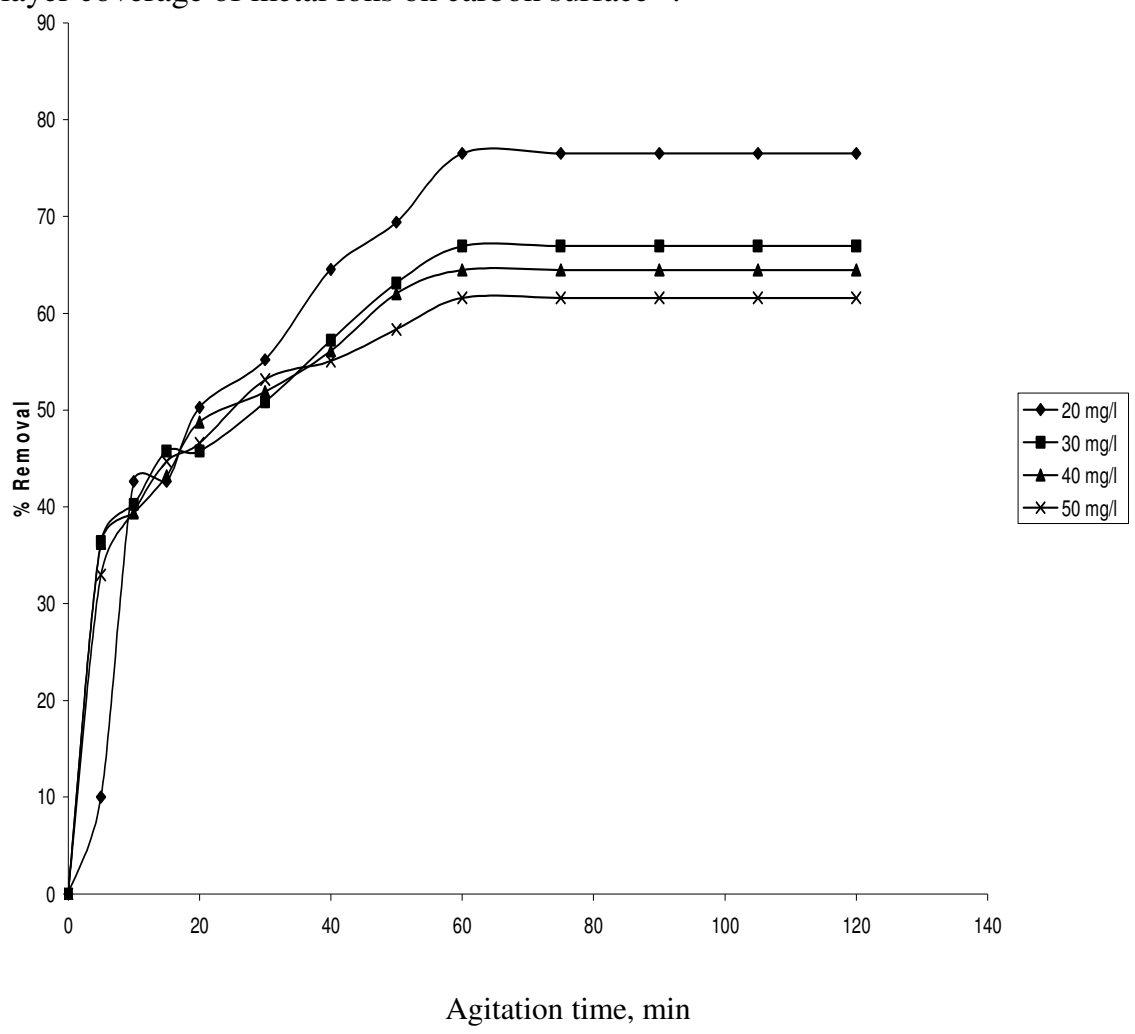

Figure 2 Effect of agitation time on $\mathrm{Cu}(\mathrm{II})$ ion removal

\section{Adsorption Kinetics}

Lagergren Rate Equation

The kinetics of $\mathrm{Cu}(\mathrm{II})$ adsorption on Sago waste carbon follows first order rate expression given by Lagergren. 
$\log \left(\mathrm{q}_{\mathrm{e}}-\mathrm{q}\right)=\log \mathrm{q}_{\mathrm{e}}-\left(\mathrm{K}_{\mathrm{ad}} \mathrm{t} / 2.303\right)$

Where, $\mathrm{q}_{\mathrm{e}}=$ The amount of $\mathrm{Cu}$ (II) adsorbed at equilibrium $(\mathrm{mg} / \mathrm{g})$

$\mathrm{Q}=$ The amount of $\mathrm{Cu}(\mathrm{II})$ adsorbed at time $\mathrm{t}$ (mins)

$\mathrm{K}_{\mathrm{ad}}=$ The rate constant of adsorption of $\mathrm{Cu}(\mathrm{II})$ by sago waste carbon

The linear plots of $\log \left(\mathrm{q}_{\mathrm{e}}-\mathrm{q}\right)$ vs $\mathrm{t}$ show the applicability of the above equation for the adsorption of $\mathrm{Cu}$ (II) by sago waste carbon. The values of $\mathrm{K}_{\mathrm{ad}}$ were calculated from the slope of the linear plots and are presented in Figure 3 for different concentration of the metal ion.

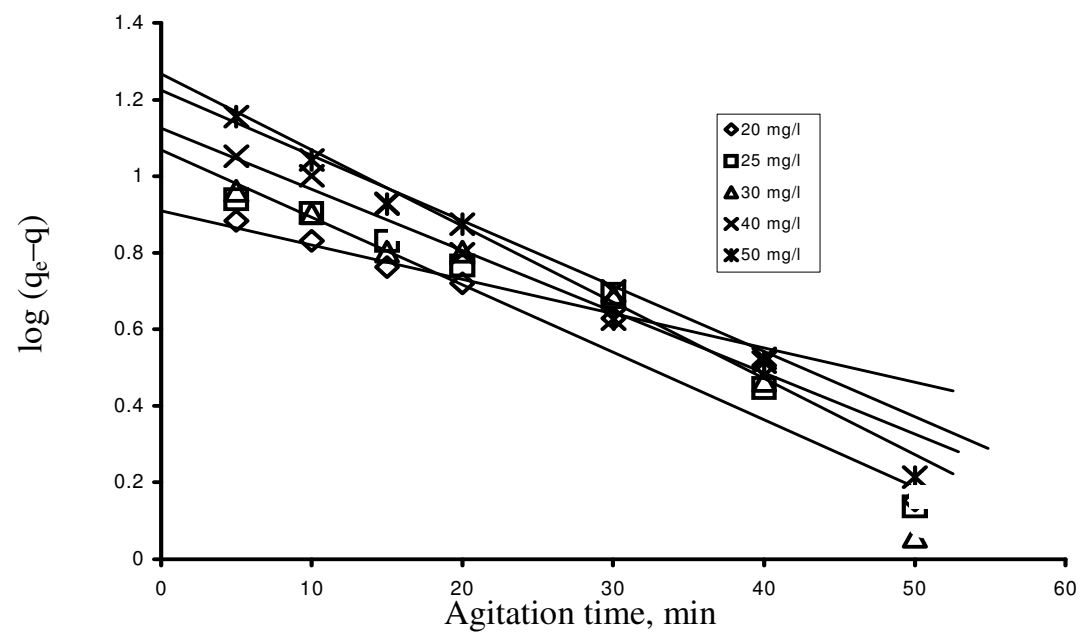

Figure 3. Lagergren plots for $\mathrm{Cu}(\mathrm{II})$ adsorption plots of $\log \left(\mathrm{q}_{\mathrm{e}} \mathrm{-q}\right) V s$ time

\section{Effect of Carbon dosage on Cu(II) Removal}

Figure 4 shows that the removal of metal ions increased with increase in carbon dosage and attained a maximum after a particular carbon concentration. It was observed from the results that the complete removal of $\mathrm{Cu}(\mathrm{II})$ from $50 \mathrm{~mL}$ of 25 and $50 \mathrm{mg} / \mathrm{L}$ required a maximum carbon dosage of 175 and $225 \mathrm{mg}$ respectively. The increase in the percent removal of $\mathrm{Cu}$ (II) with the increase in carbon dosage is due to the availability of larger surface area with more active functional groups at higher adsorbent dosage and saturation occurs as a result of non-availability of active sites on the adsorbent.

\section{Adsorption Isotherm}

Several mathematical models, such as those derived by Langmuir and Freundlich, are capable of describing the distribution of metal ions between the liquid phase and the solid phase. It is very important to have a satisfactory description of the equilibrium state between the two phases in order to successfully represent the dynamic behaviour of any adsorbate from solution to the solid (carbon) phase.

The Langumir isotherm was applied for adsorption equilibrium of $\mathrm{Cu}$ (II) onto sago waste carbon.

$$
\mathrm{C}_{\mathrm{e}} / \mathrm{q}_{\mathrm{e}}=\left(1 / \mathrm{Q}_{0} \mathrm{~b}\right)+\left(\mathrm{C}_{\mathrm{e}} / \mathrm{Q}_{\mathrm{o}}\right)
$$

Where, $\mathrm{C}_{\mathrm{e}}=$ Concentration of $\mathrm{Cu}$ (II) at equilibrium (mg/L).

$\mathrm{q}_{\mathrm{e}}=$ Amount of metal ion adsorbed at equilibrium time $(\mathrm{mg} / \mathrm{g})$.

$\mathrm{Q}_{0}=$ Adsorption capacity $(\mathrm{mg} / \mathrm{g})$.

$\mathrm{B}=$ Langmuir constant. 


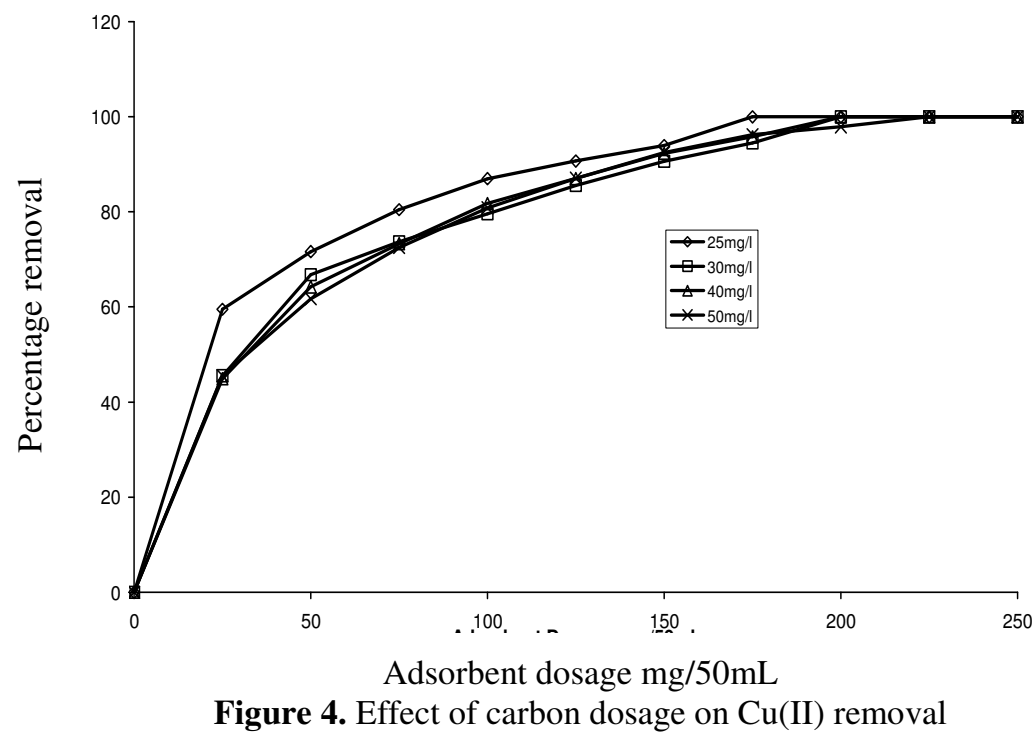

Linear plot of $\mathrm{C}_{\mathrm{e}} / \mathrm{q}_{\mathrm{e}}$ vs $\mathrm{C}_{\mathrm{e}}$ shows that the adsorption follows Langmuir isotherm model (Figure 5). The values of $\mathrm{Q}_{\mathrm{o}}$ and $\mathrm{b}$ were determined from the slope and intercept of the plot and were found to be $\mathrm{Q}_{0}=32.467 \mathrm{mg} / \mathrm{g}$ and $\mathrm{b}=0.2173 \mathrm{~L} / \mathrm{mins}$. The applicability of Langmuir isotherm suggests the monolayer coverage of $\mathrm{Cu}(\mathrm{II})$ on the surface of activated carbon prepared from sago waste.

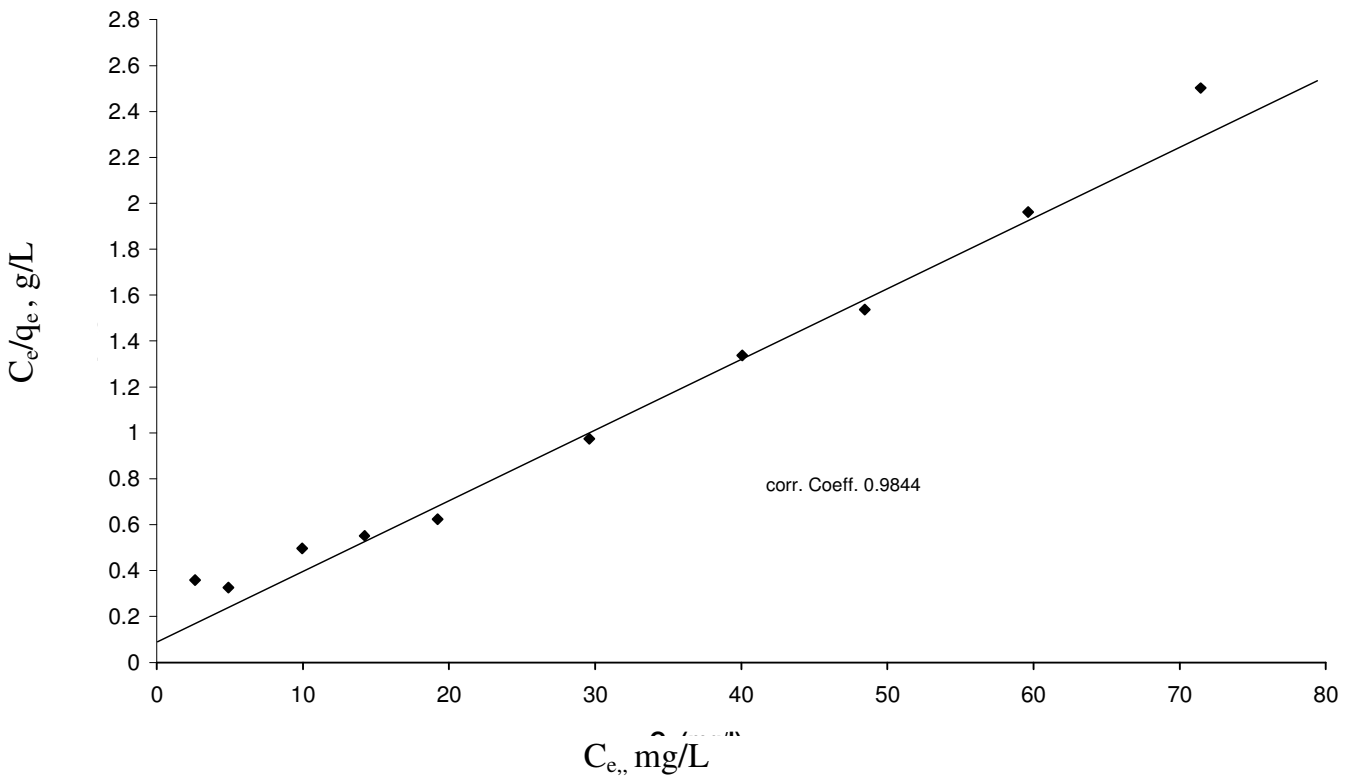

Figure 5. Langmuir Plot for $\mathrm{Cu}$ (II) 
The essential characteristics of Langmuir isotherm can be expressed in terms of dimensionless separation factor or equilibrium parameter $\mathrm{R}_{\mathrm{L}}$ that is defined by,

Where, $\mathrm{C}_{\mathrm{o}}=$ Initial $\mathrm{Cu}(\mathrm{II})$ concentration $(\mathrm{mg} / \mathrm{L})$

$$
\mathrm{R}_{\mathrm{L}}=1 / 1+\mathrm{bC}_{\mathrm{o}}
$$

$\mathrm{b}=$ Langmuir constant $(\mathrm{L} / \mathrm{mg})$

The parameter, $\mathrm{R}_{\mathrm{L}}$ indicates the shape of the isotherm as follows.

\begin{tabular}{ll}
\hline $\mathrm{R}_{\mathrm{L}}$ Value & Type of Isotherm \\
\hline $\mathrm{R}_{\mathrm{L}}>1$ & Unfavourable \\
$\mathrm{R}_{\mathrm{L}}=1$ & Linear \\
$\mathrm{C}_{\mathrm{o}}<\mathrm{R}_{\mathrm{L}}<1$ & Favourable \\
$\mathrm{R}_{\mathrm{L}}=0$ & Irreversible \\
\hline
\end{tabular}

The $R_{L}$ values obtained were in the range of 0 to $1(0.043$ to 0.31$)$ for $\mathrm{Cu}(\mathrm{II})$ concentration of 10 to $100 \mathrm{mg} / \mathrm{l}$, which indicates favourable adsorption of $\mathrm{Cu}$ (II) onto Sago waste carbon.

\section{Freundlich Isotherm}

The Freundlich equation can be derived by assuming that the free energy of adsorption decreases logarithmically as adsorption density increases. The Freundlich equation is used for heterogeneous surface energies. The linear form of Freundlich equation is given by the following expression

Where,

$$
\log (\mathrm{x} / \mathrm{m})=\log \mathrm{K}_{\mathrm{f}}+1 / \mathrm{n} \log \mathrm{C}_{\mathrm{e}}
$$

$\mathrm{X}=$ Amount of $\mathrm{Cu}$ (II) adsorbed at equilibrium (mg).

$\mathrm{M}=$ Weight of the adsorbent used ( $\mathrm{g}$ ).

$\mathrm{C}_{\mathrm{e}}=$ Equilibrium metal ion concentration $(\mathrm{mg} / \mathrm{L})$.

$\mathrm{K}_{\mathrm{f}}$ and $\mathrm{n}=$ Freundlich constants.

Linear plots of $\log _{10} \mathrm{x} / \mathrm{m}$ versus $\log _{10} \mathrm{C}_{\mathrm{e}}$ shows that the adsorption follows Freundlich isotherm model. $\mathrm{K}_{\mathrm{f}}$ and $\mathrm{n}$ values were calculated from the intercept and slope of the plots (Figure 6).

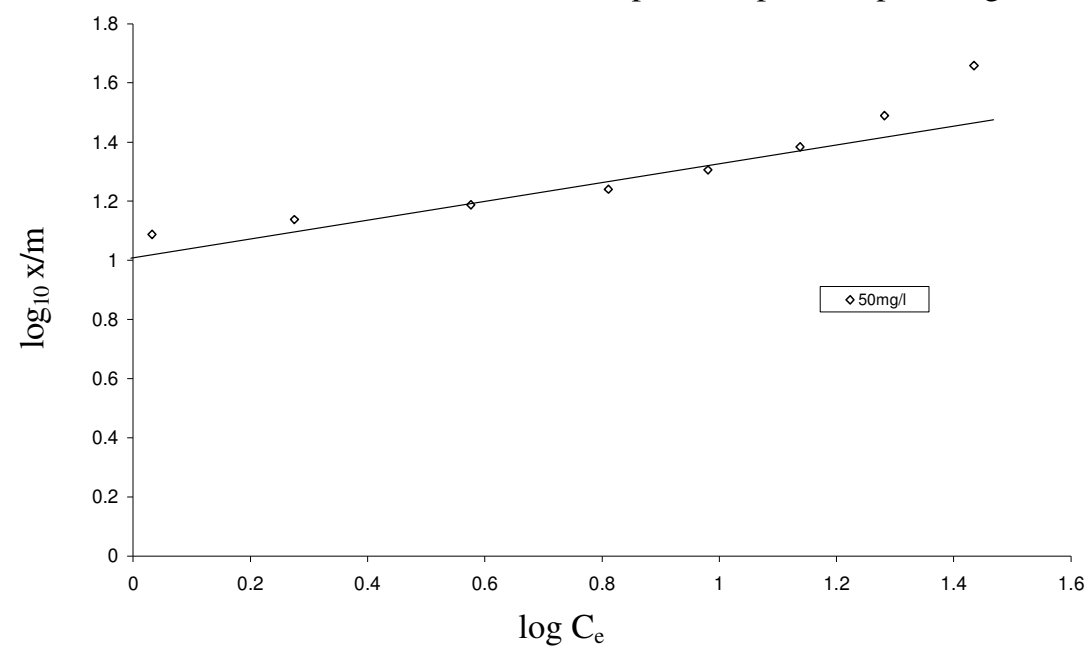

Figure 6. Freundlich plot for $\mathrm{Cu}$ (II) adsorption

Since the ' $n$ ' values in the range of 1 to 10 indicate beneficial adsorption, the values of $\mathrm{n}$ suggest that sago waste carbon may consider as an effective adsorbent. 


\section{Effect of $\mathrm{pH}$ on the adsorption of $\mathrm{Cu}(\mathrm{II})$}

Figure 7 presents the effect of initial $\mathrm{pH}$ on the removal of $\mathrm{Cu}(\mathrm{II})$ ions from aqueous solution by sago waste carbon.

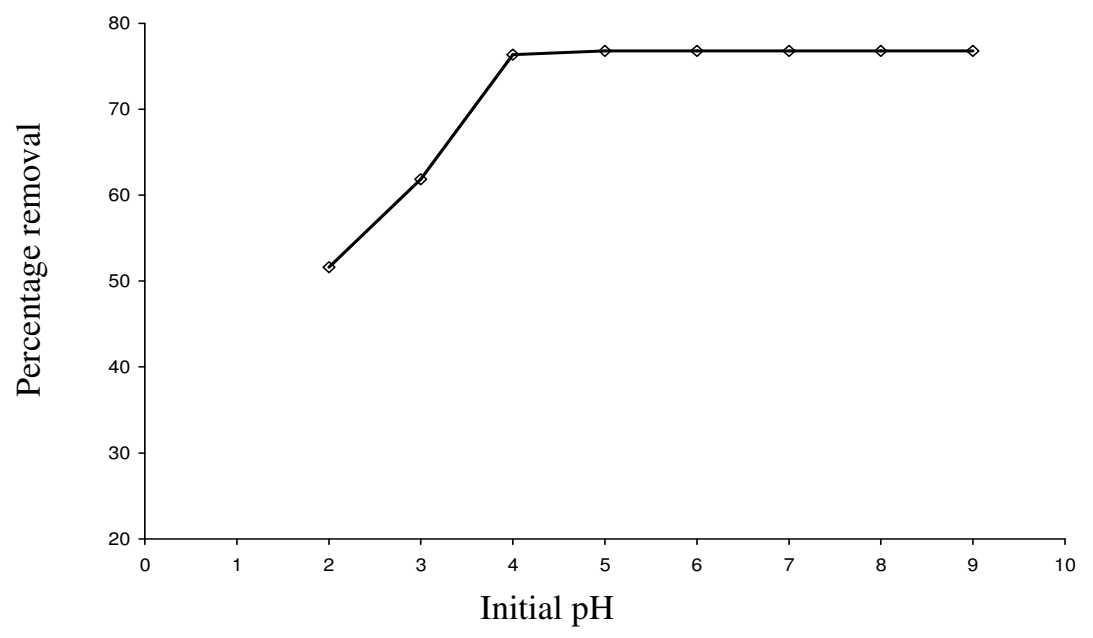

Figure 7. Effect of $\mathrm{pH}$ on $\mathrm{Cu}(\mathrm{II})$ adsorption

Adsorption of $\mathrm{Cu}(\mathrm{II})$ ion increases with increase in $\mathrm{pH}$ value from 2 to 4 and the removal is constant for further increase in $\mathrm{pH}$. Adsorption of metal ion depends upon the nature of the adsorbent surface and species distribution of the metal ion. Species distribution mainly depends on the $\mathrm{pH}$ of the system. The influence of $\mathrm{pH}$ on $\mathrm{Cu}$ (II) removal may be acidic $\mathrm{pH}$ conditions; both adsorbent and adsorbate are positively charge $\left(\mathrm{M}^{2+}\right.$ and $\left.\mathrm{H}^{+}\right)$and therefore the interaction is that of electrostatic repulsion ${ }^{8,18}$. Beside, the higher concentration of $\mathrm{H}^{+}$ions for the surface adsorbing sites results in decrease in the removal of $\mathrm{Cu}(\mathrm{II})$. The concentration of $\mathrm{Cu}$ (II) remains constant resulting in increase in the removal of $\mathrm{Cu}(\mathrm{II})$. The significant adsorption of metal ions is observed below $\mathrm{pH} 4.5$. At $\mathrm{pH}>5$ precipitation of $\mathrm{Cu}(\mathrm{OH})_{2}$ takes place. Hence it was decided to maintain the $\mathrm{pH}$ at $4 \pm 0.5$ for all other studies.

\section{Conclusion}

Activated carbon prepared from sago waste can be used as an adsorbent for the effective removal of $\mathrm{Cu}(\mathrm{II})$ from aqueous solution. Analysis of SEM images showed that the sago waste surface was rough and possessed micropores. Adsorption depends on the solution $\mathrm{pH}$, the initial $\mathrm{Cu}$ (II) concentration, the carbon dose employed and the particle size of the adsorbent. Adsorption of $\mathrm{Cu}$ (II) increased with increasing agitation time, carbon concentration and decreased with increasing $\mathrm{pH}$ and $\mathrm{Cu}(\mathrm{II})$ concentration. Adsorption equilibrium was reached with in a short period of time (60 minutes). The adsorption was found to obey Lagergren equation and the Lagergren rate constant for adsorption of $\mathrm{Cu}$ (II) was found to be constant for various initial concentrations of $\mathrm{Cu}(\mathrm{II})$, which implies that adsorption follows first order kinetics. Adsorption of $\mathrm{Cu}$ (II) from aqueous solution increased with decreasing particle size of the adsorbent and increased with increasing carbon concentration. Adsorption of $\mathrm{Cu}(\mathrm{II})$ onto activated carbon obeyed both Langmuir and Freundlich model. The maximum adsorption capacity $\left(\mathrm{Q}_{\mathrm{o}}\right)$ calculated from Langmuir Isotherm was found to be $32.407 \mathrm{mg} / \mathrm{L}$ for the particle size of $125-250 \mu$. Freundlich adsorption capacity was found to be 5.260. Freundlich constant and $R_{L}$ values $(0.0439-0.315)$ 
from Langmuir Isotherm indicate that the adsorption process is favorable for the removal of $\mathrm{Cu}(\mathrm{II})$ by sago waste carbon. The present investigation shows that the sago waste activated carbon can be employed as an effective adsorbent for the removal of $\mathrm{Cu}$ (II) from aqueous solution. Since the raw material used in the preparation of activated carbon is available abundantly, the resulting carbon is expected to be economically viable.

\section{Reference}

1. King P, Parasanna Kumar V and Prasad V S R K, Journal of Industrial Pollution Control, 2005, 21(1), 155-162

2. Matheickal J T, Leela lyengar and Venkobachar C, Kes. J. Canda., 1991, 26, 187

3. Sreenivasa Rao, Ramkrishna B and Venkateswaralu P, INEP., 2003, 23(10), 1141-1145

4. Viashya R K and Prasad S C, Ind. J. Environ Pollution, 1991, 11, 284-289

5. Narsi R., Bishnoi, Anju Pant and Garima, Indian Journal of Science and Industrial Research, 2004, 63, 813-816

6. Sharma, C.B and Giri B D, Journal of Scientific and Industrial Research, 1996, 551, 156-162

7. Kannan K, Fundamental of Environmental Pollution, S.Chand \& Co., Ltd., 1995

8. Namasivayam C and Periasamy K, Wat Res., 1993, 27, 1667-1672

9. Streat M, Partick W and Camporro perex M J, Wat Res., 1995 29(2), 467-72

10. Navarro R R, Sumi K, Fujii N and Matsumuta M, Wat Res., 1996, 30, 2488-94.

11. Kadirvelu K, Kanmani P, Senthi Kumar and Subburam V, Science Technology, 2004, 22, 207

12. Boehm H P, Carbon 1994, 32, 759-69.

13. Xiaoge C, Jayaseelan S and Graham N, Waste Manage, 2002, 22, 755-60.

14. Periasamy K and Namasivayan, Chemosphere, 1996, 32, 769-789

15. Murat Tekes, Mustafa and Omer Saltabas, Turk. J. Chemistry, 1999, 23, 185-191

16. Helen Kalavathy M, Karthikeyan., Rajagopal and Lina Rose, Journal of Colloid and Interface Science, 2005, 292(2), 354-362

17. Anoop K K. and Anirudhan, J.Haz.Mater., 2002, B92L161, 83

18. Namasivayam C and Kadirvelu K, Carbon, 1999, 37, 79 


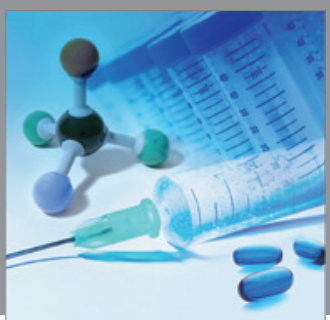

International Journal of

Medicinal Chemistry

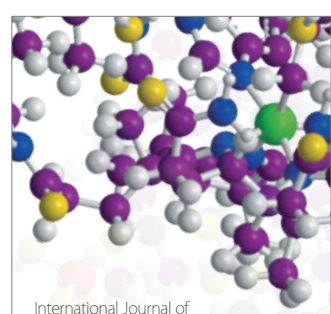

Carbohydrate Chemistry

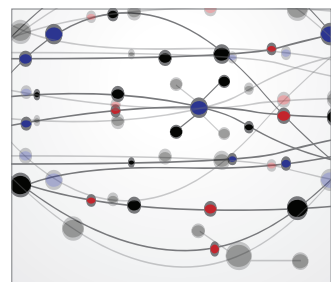

The Scientific World Journal
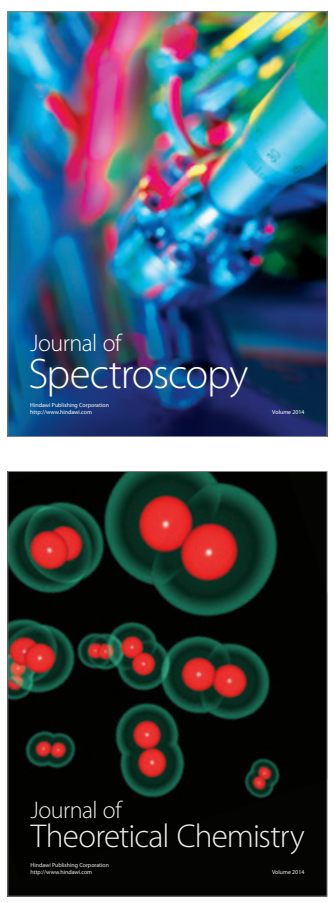
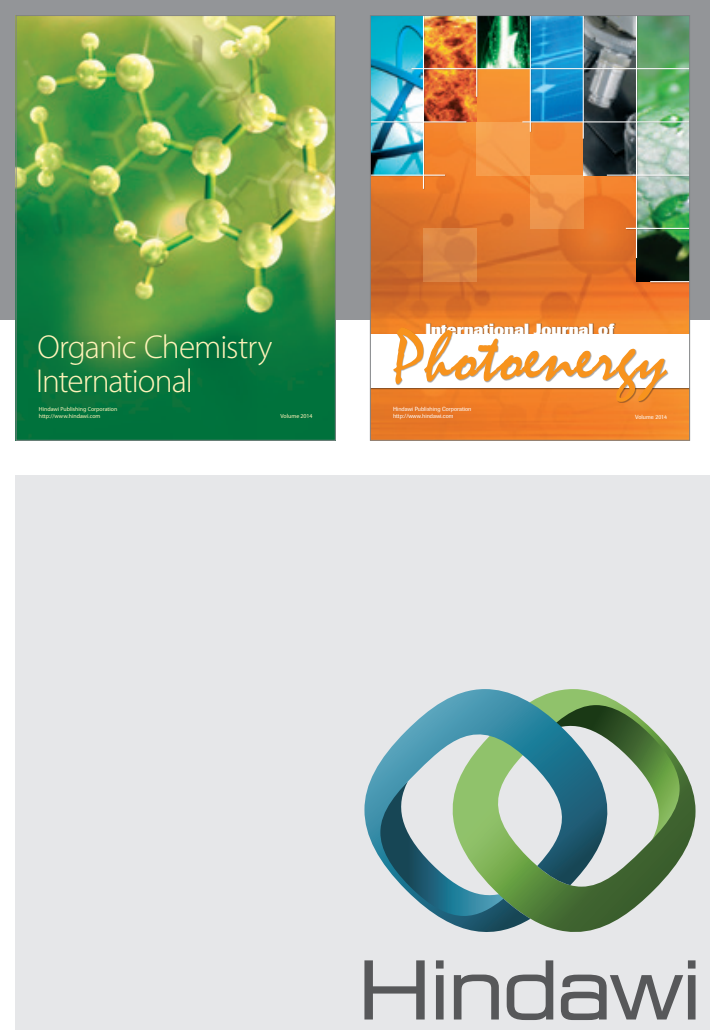

Submit your manuscripts at

http://www.hindawi.com
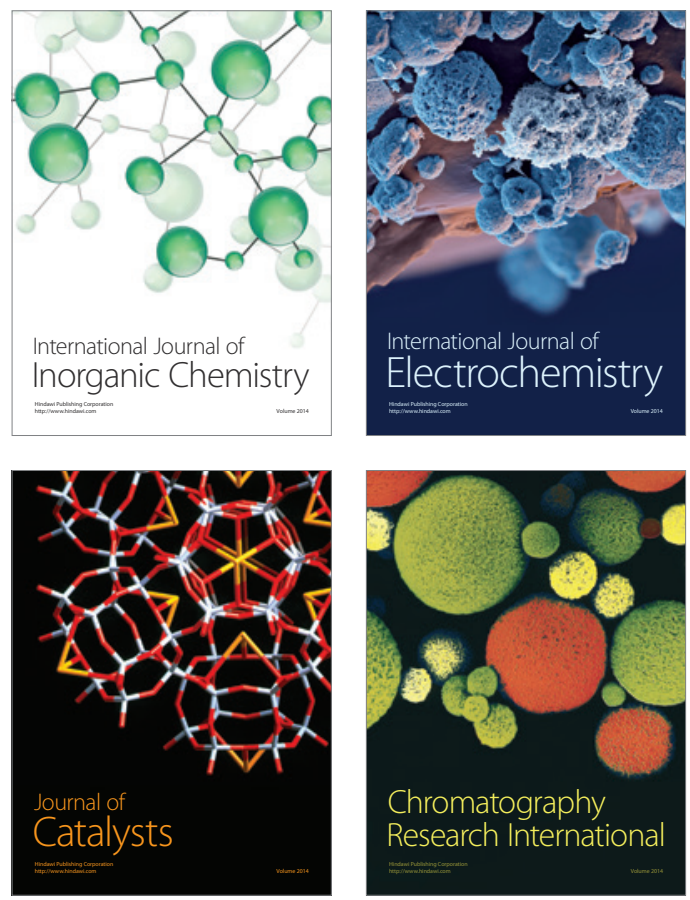
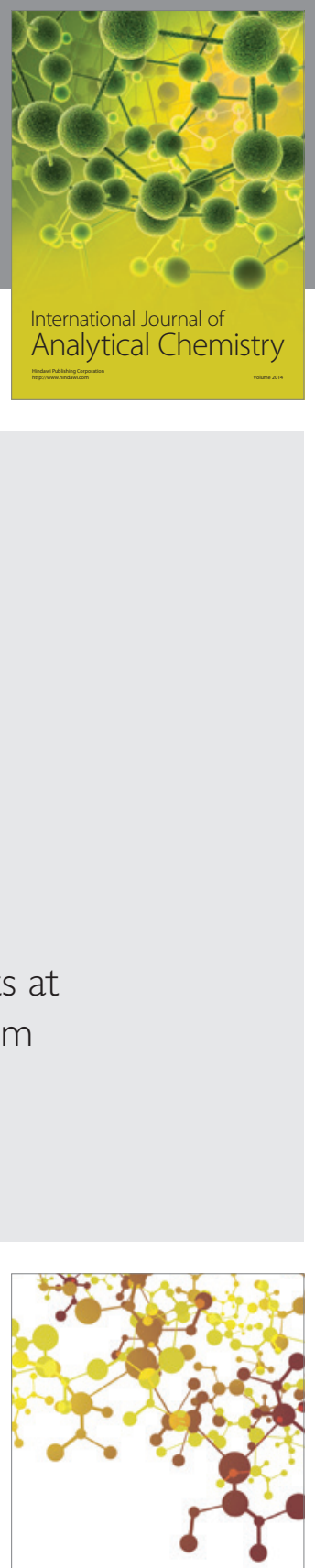

Journal of

Applied Chemistry
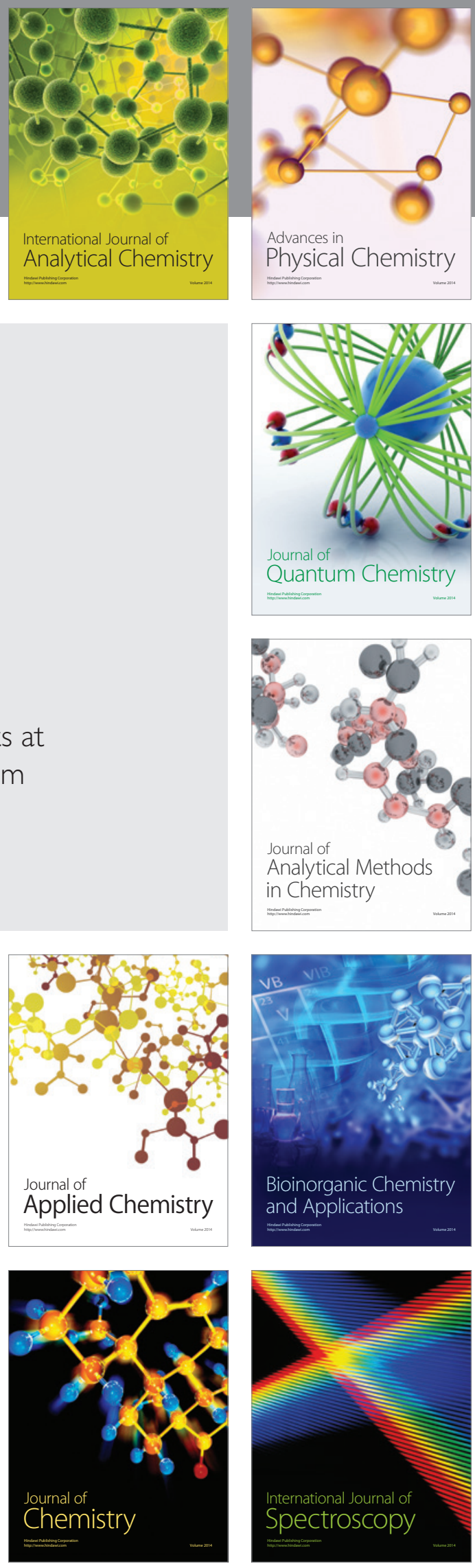